\title{
HUBUNGAN PENGETAHUAN SILA KEMANUSIAN DENGAN SIKAP TENGGANG RASA PADA SISWA SDN CIBARUSAH JAYA 01 KECAMATAN CIBARUSAH KABUPATEN BEKASI (Studi Korelasional pada Siswa Kelas V SD)
}

\author{
Yayan Alpian \\ Fakultas Keguruan dan Ilmu Pendidkan UBP Karawang \\ Yayan.alpian@ubpkarawang.ac.id
}

\begin{abstract}
This research aims to know about the relationship of humanity with sila knowledge attitude of tolerance. This research was carried out in Cibarusah Jaya SDN 01 Cibarusah Bekasi, research methods used is the method of the study of the correlation of quantitative descriptive research. The population of this research is the whole student in Cibarusah Jaya SDN 01 with number of sempel 40 people from a class $V$. The instruments used for the knowledge of humanity which is sila free variables using multiple choice tests, whereas the attitude of tolerance which is a variable using a scale of attitude with alternative answers agree $(S)$, undecided $(R)$, disagree $(T S)$. Test requirements the data analysis done with test for Normality (Liliefors) and Linieritas test. To test the Normality of the knowledge humanity sila retrieved Lo count 0.095 and attitudes of tolerance retrieved Lo table of 0.1401, then the population data comes from the Gaussian. To test linieritas (Liliefors) produces a count of $1.390 \mathrm{~F}$ and $F$ table of 2.29. Thus $F$ count smaller than F table (1.390 > 2.29). Then it is revealed that the linear-shaped data. Analysis data to test hypotheses using the correlation formula product moment (rxy), at a significant level $\alpha=0.05$ and $N$ $=40$ Students produce $r$ table of 0.312 and $r$ count of 0.311 . This means $r$ count smaller than $r$ table $(0.11<0,312)$. Thus it can be concluded the research hypothesis was rejected because there is no relationship of humanity with sila knowledge attitude of tolerance in elementary school the country Cibarusah Jaya 01 Cibarusah Bekasi. To test the significance of the correlation coefficient is used t-tests, $2.256 t$ and tobtained on the significance level $\alpha=0.05$ with $d k=38$ of 2.02 , thus $t$ is greater than $t(2.265>2.02)$. This means the correlation of these two variables is meaningless. While the magnitude of the contribution of the variable $X$ against $Y$ variables are viewable from the determination coefficient i.e. of $9.6 \%$. and it can be concluded that there is no relationship of humanity with sila knowledge attitude of tolerance in elementary school the country Cibarusah Jaya 01 Cibarusah Bekasi.

Keyword: humanity, tolerance
\end{abstract}

\begin{abstract}
ABSTRAK
Penelitian ini bertujuan ingin mengetahui mengenai hubungan pengetahuan sila kemanusian dengan sikap tenggang rasa. Penelitian ini dilaksanakan di SDN Cibarusah Jaya 01 Cibarusah Bekasi, metode penelitian yang digunakan adalah metode studi korelasi yang merupakan bagian dari penelitian deskriptif kuantitatif. Populasi penelitian ini adalah seluruh siswa di SDN Cibarusah Jaya 01 dengan jumlah sempel sebanyak 40 orang dari kelas V. Instrumen yang digunakan untuk pengetahuan sila kemanusian yang merupakan variabel bebas menggunakan tes pilihan ganda, sedangkan sikap tenggang rasa yang merupakan variabel terikat mengunakan skala sikap dengan alternatif jawaban setuju (S), ragu-ragu $(\mathrm{R})$, tidak setuju (TS).

Uji persyaratan analisis data dilakukan dengan uji Normalitas (Liliefors) dan uji Linieritas. Untuk uji Normalitas pengetahuan sila kemanusian diperoleh Lo hitung sebesar 0,095 dan sikap tenggang rasa diperoleh Lo tabel sebesar 0,1401, maka populasi berasal
\end{abstract}


dari data berdistribusi normal. Untuk uji linieritas (Liliefors) menghasilkan $\mathrm{F}$ hitung sebesar 1,390 dan F tabel sebesar 2,29. Dengan demikian F hitung lebih kecil dari F tabel $(1,390>2,29)$. Maka dinyatakan bahwa data berbentuk linier.

Analisis data untuk menguji hipotesis menggunakan rumus korelasi product moment $\left(\mathrm{r}_{\mathrm{xy}}\right)$, pada taraf signifikan $\alpha=0,05$ dan $\mathrm{N}=40$ Siswa menghasilkan $\mathrm{r}$ tabel sebesar 0,312 dan $r$ hitung sebesar 0,311 . Ini berarti $r$ hitung lebih kecil dari $r$ tabel $(0,11<0,312)$. Dengan demikian dapat disimpulkan hipotesis penelitian ditolak karena tidak ada hubungan pengetahuan sila kemanusian dengan sikap tenggang rasa di Sekolah Dasar Negeri Cibarusah Jaya 01 Cibarusah Bekasi.

Untuk menguji signifikansi koefisien korelasi digunakan uji-t, diperoleh $\mathrm{t}_{\text {hitung }}$ 2,256 dan $\mathrm{t}$ tabel pada taraf signifikasi $\alpha=0,05$ dengan $\mathrm{dk}=38$ sebesar 2,02, dengan demikian $t_{\text {hitung }}$ lebih besar dari $t_{\text {tabel }}(2,265>2,02)$. Hal ini berarti korelasi kedua variabel adalah berarti. Sedangkan besarnya kontribusi variabel $\mathrm{X}$ terhadap variabel $\mathrm{Y}$ adalah dapat dilihat dari koefisien determinasi yaitu sebesar 9,6\%. dan dapat disimpulkan bahwa tidak terdapat hubungan pengetahuan sila kemanusiaan dengan sikap tenggang rasa di Sekolah Dasar Negeri Cibarusah Jaya 01 Cibarusah Bekasi.

Keywords: Sila Kemanusian, Sikap Tenggang Rasa

\section{PENDAHULUAN}

Manusia adalah makhluk sosial (zoon politicon) bermakna luas. Sebagai makhluk sosial, manusia tidak akan dapat lepas dari sebuah hubungan atau interaksi, baik interaksi dengan kelompoknya maupun dengan lingkungan yang lain. Hubungan manusia dengan manusia, manusia dengan mahkluk lain (hewan dan tumbuhan), serta manusia dengan lingkungannya adalah hukum alam yang harus dijalani oleh setiap makhluk di dunia ini. Tidak semena-mena terhadap orang lain, saling menghormati merupakan perwujudan dari sikap menghargai dan mengakui adanya persamaan derajat di antara ssama manusia. Sikap perduli dan tanggap serta peka terhadap lingkungan juga merupakan bentuk lain dari pengakuan adanya keberadaan orang lain yang akan saling membutuhkan.

Tenggang rasa atau tepa selira adalah sikap seseorang yang menempatkan perasaannya pada perasaan orang lain. Konsep tenggang rasa identik dengan konsep mencintai, menghargai sesama manusia. Penghargaan yang timbul antara sesama manusia adalah upaya untuk menjaga kehidupan sosial yang ada. Sikap menghargai, menghormati, saling menjaga, saling memperhatikan adalah sikap-sikap yang harus dibangun dan dikembangkan dalam bermasyarakat. Hal tersebut bukanlah suatu pekerjaan mudah, karena tidak setiap orang mempunyai kemampuan yang sama untuk berintraksi.

Sikap tenggang rasa menjadi hal penting yang harus dimiliki oleh setiap orang, bukan hanya hal tersebut dianjurkan oleh dasar hukum negara kita (Pancasila) sebagai satusatunya falsafah hidup bangsa Indonesia, tetapi karena kita sendiri harus menyadari bahwa kita tidak akan bisa hidup dengan baik tanpa ada orang lain yang membantu kita. Inilah kodrat manusia, sebagai makhluk Tuhan, makhluk pribadi sekaligus makhluk sosial. Tanpa ada manusia lain atau tanpa hidup bermasyarakat, seseorang tidak akan dapat berbuat apaapa. Oleh karenanya, sila kemanusian yang adil dan beradab, sangatlah tepat menempatkan butir-butir saling mencintai, menjungjung tinggi nilai kemanusian, mengakui persamaan hak, derajat dan saling menghormati serta menghargai antar sesama, sebagai acuan sikap yang harus dilakukan oleh bangsa Indonesia. Hal tersebut tentu saja sebagai perwujudan dari upaya bangsa ini untuk senantiasa tidak melupakan kodrat manusia yang hakiki.

Sikap tenggang rasa atau merasakan apa yang orang lain rasakan (dalam arti positif) adalah suatu sikap yang tidak tumbuh begitu saja dalam diri seseorang. Ada proses pembelajaran yang harus dilakukan secara terus menerus oleh individu tertentu agar 
memiliki sikap tersebut. Proses ini bisa di pupuk dan dikembangkan sejak dini, baik dalam lingkungan keluarga yang paling asasi dalam masyarakat maupun dalam lingkungan pendidikan formal (sekolah).

Menurut H.A.R. Tilaar (1999: 80) pendidikan merupakan sebagian dari kehidupan masyarakat dan juga sebagai dinamisator masyarakat itu sendiri. Pendidikan di sekolah mempunyai tanggung jawab yang besar sebagai tempat bagi para siswa mengasah diri, kepribadian, dan kemampuan untuk memiliki sifat-sifat positif dan nilai-nilai luhur yang dapat diterapkannya dalam kehidupan bermasyarakat. Sikap peduli terhadap lingkungan harus ditanamkan sebaik mungkin agar kelak siswa tidak memiliki kecenderungan sikap ambivalensi atau tidak peduli sama sekali dan pasif, sihingga tidak mau melakukan hal-hal yang sebenarnya harus dilakukan. Dalam kehidupan di sekolah selain pendidikan moral, peran sekolah sebagai Laboratorium etik dan moral peserta didik yaitu sebagai tempat untuk menciptakan kepatuhan terhadap norma-norma sosial baru seperti ketertiban, disiplin dalam tata kehidupan bersama, kebiasaan-kebiasaan hidup serta moral yang tinggi menjadi sangat dominan dalam membentuk karakter sosial peserta didik (H.A.R. Tilaar, 1999: 174).

Fenomena yang terjadi pada siswa-siswi di SDN Cibarusah Jaya 01 semakin memperihatikan saat ini, karena semakin memudarnya rasa kebersamaan dan tenggang rasa yang ada di lingkungan SDN Cibarusah Jaya 01. padahal, jauh sebelumnya SDN Cibarusah Jaya 01 para siswa-siswinya ramah-ramah, memiliki tingkat keperdulian yang tinggi, memiliki sikap tenggang rasa yang baik, cukup membanggakan bagi masyarakat sekitar. Hal sebaliknya justru terjadi, berbagai hal yang menjadi contoh saat ini adalah berkembanya sikap ego dan individualistis yang akan menggantikan sikap tenggang rasa yang ada.

Walaupun di sekolah sudah diajarkan mata pelajaran PPKn, Agama, serta nilainilai budi pekerti khususnya tentang rasa, namun belum sepenuhnya dilaksankan oleh para siswa karena sering terjadi perkelahian diantara sesama teman, kurang sopannya siswa tehadap guru, bahkan ada siswa yang sering melawan guru dan akhirnya mengadu domba antara orang tua murid dengan guru. Oleh karena itu siswa-siswi di SDN Cibarusah Jaya 01 pada kenyataanya masih banyak siswa yang belum memahami. Contohnya diantaranya adalah sikap fanatik yang berlebihan, yakni sikap tidak menghargai umat/siswa lain yang agamanya berbeda, sikap acuh tak acuh terhadap siswa yang terkena musibah, mengejek dan menghina temannya yang kurang mampu, tidak mau mengendalikan diri dari ucapan dan perbuatan yang menyinggung perasaan orang lain.

Pancasila sebagai dasar negara adalah jiwa seluruh rakyat indonesia serta merupakan kepribadian dan pandangan hidup bangsa Indonesia. Keberadaan pancasila bukan hanya sebagai lambang dan selogan semata, tetapi harus dapat diterima dan dijadikan sebagai pedoman bangsa Indonesia dalam keidupan sehari-hari. Pancasila lahir dan pergumulan nyata bangsa Indonesia. Ia tumbuh dari amanat penderitaan rakyat, karena itu Pancasila berakar pada kepribadian bangsa kita sendiri. Ia menyentuh kehidupan seharihari yang nyata. Mengamalkan Pancasila tidak lain dari pada melaksanakan sesuatu yang berguna, baik atau luhur dalam kehidupan sehari-hari terutama dalam mewujudkan masyarakat Pancasila. Dalam menegakkan dan mengatur Negara Pancasila, tugas luhur manusia Indonesia adalah dengan kesungguhan hati dan penuh rasa tanggung jawab melaksanakan dan menjadikan Pancasila dalam perilaku sehari-hari (C.S.T.Kansil, 1993: 93).

Untuk melestarikan dan menjadikan Pancasila sebagai landasan idiil (landasan paling mendasar) dalam kehidupan berbangsa dan bernegara, perlu diusahakan secara nyata dan terus menerus penghayatan dan pengalaman nilai-nilai yang terkandung di dalamnya oleh setiap warga negara Indonesia. Lebih dari itu, harus diyakini bahwa Pancasila tersebut dapat memberi kekuatan hidup serta membimbing bangsa Indonesia menjalankan 
kehidupan lahir dan batin yang semakin baik di dalam masyarakat Indonesia yang adil dan makmur. Oleh karenanya, Pancasila harus kita amalkan dalam kehidupkan nyata seharihari baik dalam kehidupan pribadi, masyarakat, ataupun negara.

Salah satu nilai yang dikedepankan Pancasila untuk difahami dan diterima oleh manusia Indonesia adalah nilai kemanusiaan. Nilai ini ditempatkan pada kedudukan yang sangat urgen nilai Ketuhanan. Hal ini berarti bahwa nilai kemanusiaan atau yang lebih lengkap disebut sila kemanusiaan yang adil dan beradab, adalah hal yang sangat penting yang harus dijunjung tinggi oleh manusia Indonesia khususnya, sehingga pemerintah dalam hal ini kemudian merumuskan sila kemanusiaan menjadi sila kedua dalam Pancasila. Dengan sila ke-2 ini, manusia diakui dan diperlakukan sesuai dengan harkat dan martabatnya sebagai makhluk Tuhan Yang Maha Esa, yang sama derajatnya, sama hak dan kewajiban-kewajiban asasinya, tanpa membeda-bedakan suku, keturunan, agama, dan kepercayaan, jenis kelamin, kedudukan sosial, warna kulit, dan sebagainya. Karena itu dikembangkan sikap saling mencintai sesama manusia, sikap tenggang rasa, dan tepa selira serta sikap tidak semena-mena terhadap orang lain. Hal ini kemudian mendasari bentukbentuk kebersamaan yang lebih serasi karena nilai-nilai tersebut dapat menjadi faktor yang sangat menentukan bobot kebersamaan yang ingin kita wujudkan. Dalam Pancasila, tidak ada tempat untuk asas mutlak perorangan, tidak ada cara berfikir individu mutlak atau hidup yang dikelilingi tembok-tembok pemisah yang ketat dan kaku. Sebaliknya, kita dituntut untuk dapat berfikir secara menyeluruh dalam kebersamaan yang dinamis, selalu meningkat, dan berkembang.

Menurut Sunoto (1983: 3) mengemukakan pendapatnya bahwa pada hakekatnya kemanusiaan adalah bawaan kodrat manusia karena kemanusiaan adalah sifat atau ciri kodrat manusia. Pengejawantahannya dapat kita lihat pada tindakan manusia yang dapat kita nilai sesuai dengan kemanusiaan atau tidak. Sedangkan peri kemanusiaan adalah sesuatu yang bersumber pada kemanusiaan, jiwa yang membedakan dengan makhluk lainnya.

Pengetahuan sila kemanusiaan yang adil dan beradab mempunyai nilai-nilai yang terkandung didalamnnya, antara lain; pengakuan terhadap martabat manusia, Sesama manusia mendapat pengakuan yang adil, pengertian manusia beradab yang memiliki daya cipta, karsa, dan keyakinan sehingga jelas perbedaannya manusia dengan hewan, nilai sila kedua diliputi dan dijiwai sila pertama yaitu menuntut agar manusia memperhatikan, menghormati serta menaati petunjuk Tuhan Yang Maha Esa.

Tenggang rasa artinya menghargai, menghormati, memahami pikiran, perasaan, dan perbuatan orang lain. Tenggang rasa diwujudkan dengan sikap menempatkan diri pada keadaan yang mengalami orang lain sehingga ikut merasakan pengalaman orang lain tersebut. Setiap manusia, tanpa terkecuali, memiliki harkat derajat dan martabat yang sama. Pengakuan akan persamaan derajat manusia itu mengandung tuntutan bagi kita untuk menjungjung nilai-nilai kemanusiaan. Tuntutan itu kita wujudkan dengan mengembangkan sikap tenggang rasa (Marga Ruswanda, dkk, 1999: 51). Sedangkan menurut Kasdi (2004: 12) bahwa tenggang rasa itu adalah sikap yang menempatkan perasaan dan penderintaan orang lain menjadi perasaan dan penderitaan kita walaupun kita tidak secara langsung mengalaminya.

Sikap tenggang rasa merupakan sikap seseorang mendapatkan perasaannya pada perasaan orang lain serta saling mencintai sesama manusia, maka akan timbul keinginan untuk dapat mencintai orang lain sebagai mana mencintai dirinya sendiri, yang berupa kecenderungan untuk bertindak, berpersepsi, berfikir dan merasakan dalam menghadapi obyek, ide dan situasi atau nilai, berupa positif, afektif, dan konatif yang meliputi kesediaan bertoleransi, menerima, saling memiliki, pandangan luas dan berjiwa besar. Dengan demikian semakin baik pengetahuan sila kemanusiaan maka akan semakin baik pula sikap tenggang rasa dan sebaliknya semakin rendah pengetahuan siswa tentang sila kemanusiaan maka akan semakin rendah juga sikap tenggang rasa, sehingga diduga ada hubungan antara pengetahuan siswa tentang sila kemanusiaan dengan sikap tenggang rasa di SDN Cibarusah Jaya 01 Kecamatan Cibarusah Kabupaten Bekasi. 


\section{METODOLOGI PENELITIAN}

Tujuan yang ingin dicapai dari penelitian ini adalah untuk mengetahui ada tidaknya hubungan pengetahuan siswa tentang sila kemanusiaan yang adil dan beradab dengan sikap tenggang rasa di Dasar Negeri Cibarusah Jaya 01 Kecamatan Cibarusah Kabupaten Bekasi. Populasi dalam penelitian ini adalah seluruh siswa Dasar Negeri Cibarusah Jaya 01 yang berjumlah 240 orang. Sample dalam penelitian diambil dari siswa kelas V Dasar Negeri Cibarusah Jaya 01 sebanyak 40 orang.

Teknik yang digunakan untuk mengumpulkan data tentang pengetahuan sila kemanusiaan yang adil dan beradab yang merupakan variabel bebas menggunakan tes yaitu bentuk pilihan ganda, dengan kategori 1 (satu) untuk jawaban yang benar dan 0 (nol) untuk jawaban yang salah. Dan untuk mengetahui data tentang sikap tenggang rasa siswa yang merupakan variabel bebas menggunakan kuisioner memakai skala sikap. Pada skala sikap ini alternatif jawabannya adalah setuju (S) dengan skor 3, ragu-ragu (R) skor 2 dan tidak setuju (TS) dengan skor 1. Adapun untuk menganalisis data menggunakan rumus kolerasi product moment.

\section{HASIL DAN PEMBAHASAN}

Secara keseluruhan skor yang diperoleh dari variabel X, yaitu pengetahuan sila kemanusian berjumlah 791, dengan skor tertinggi 27 dan skor terendah 10. dari jumlah tersebut dperoleh rata-rata $($ mean $)=19,55$ median $=23,12$, modus $=23,42$, standar devisi $=4,63$, serta varian sebesar $=21,48$.

Apabila data-data tersebut digambarkan dalam bentuk grafik histogram dan poligon, maka akan terlihat gambar seperti dibawah ini :

Tabel 1

Distribusi frekuensi untuk pembuatan grafik histogram dan poligon dari data Hubungan Pengetahuan Sila Kemanusiaan

\begin{tabular}{c|ccc} 
Kelas & F & Titik tengah & Batas Nyata \\
\hline $\mathbf{1 0}-\mathbf{1 2}$ & 4 & 11 & $\mathbf{9 , 5}-\mathbf{1 2 , 5}$ \\
$\mathbf{1 3}-\mathbf{1 5}$ & 5 & 14 & $\mathbf{1 2 , 5}-\mathbf{1 5 , 5}$ \\
$\mathbf{1 6}-\mathbf{1 8}$ & 5 & 17 & $\mathbf{1 5 , 5}-\mathbf{1 8 , 5}$ \\
$\mathbf{1 9}-\mathbf{2 1}$ & 11 & 20 & $\mathbf{1 8 , 5}-\mathbf{2 1 , 5}$ \\
$\mathbf{2 2}-\mathbf{2 4}$ & 9 & 23 & $\mathbf{2 1 , 5}-\mathbf{2 4 , 5}$ \\
$\mathbf{2 5}-\mathbf{2 7}$ & $\mathbf{6}$ & $\mathbf{2 6}$ & $\mathbf{2 4 , 5}-\mathbf{2 7 , 5}$
\end{tabular}

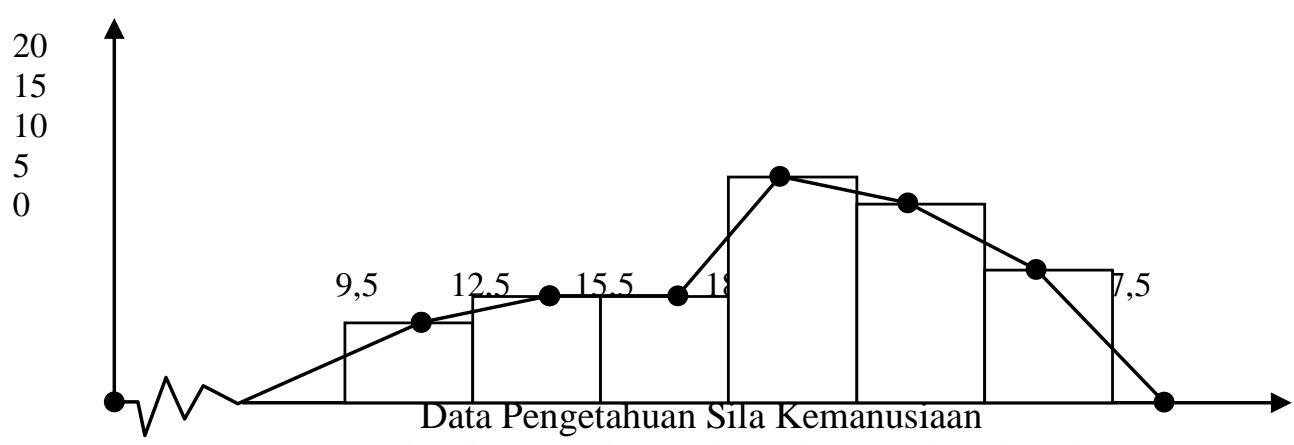

Berdasarkan grafik diatas terlihat bahwa frekuensi tertinggi terletak pada kelas interval $(18,5-21,5)$. Hal ini menunjukan bahwa pengetahuan responden terhadap sila kemanusian yang berada pada rentangan $(10-25)$ tinggi untuk sebagian responden.

Secara keseluruhan skor variabel Y (Sikap Tenggang Rasa) berjumlah 2711, dengan skor tertinggi 75 dan skor terendah 58. dari jumlah tersebut diperoleh rata-rata $($ mean $)=67,9$, median $=68,249$, modus $=68,249$, standar devisi $=4,581$, serta varian 
sebesar 10,29. apabila data-data tersebut digambarkan dalam bentuk grafik histogram dan poligon, maka dapat terlihat seperti dibawah ini. 
Tabel 2

Distribusi frekuensi untuk pembuatan grafik histogram dan poligon dari data

Sikap Tenggang Rasa

\begin{tabular}{c|ccc} 
Kelas & F & Titik Tengah & Batas Nyata \\
\hline $\mathbf{5 8}-\mathbf{6 0}$ & 3 & 59 & $\mathbf{5 7 , 5}-\mathbf{6 0 , 5}$ \\
$\mathbf{6 1}-\mathbf{6 3}$ & 5 & 62 & $\mathbf{6 0 , 5}-\mathbf{6 3 , 5}$ \\
$\mathbf{6 4}-\mathbf{6 6}$ & 5 & 65 & $\mathbf{6 3 , 5}-\mathbf{6 6 , 5}$ \\
$\mathbf{6 7}-\mathbf{6 9}$ & 12 & 68 & $\mathbf{6 6 , 5}-\mathbf{6 9 , 5}$ \\
$\mathbf{7 0}-\mathbf{7 2}$ & 7 & 71 & $\mathbf{6 9 , 5}-\mathbf{7 2 , 5}$ \\
$\mathbf{7 3}-\mathbf{7 5}$ & $\mathbf{8}$ & $\mathbf{7 4}$ & $\mathbf{7 2 , 5}-\mathbf{7 5 , 5}$
\end{tabular}

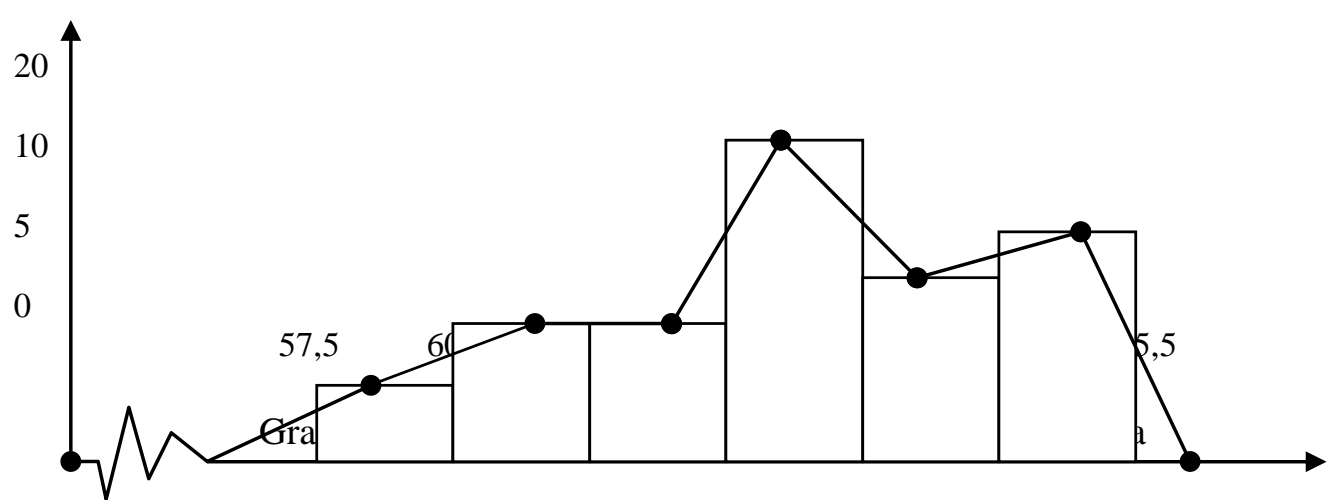

Berdasarkan grafik diatas terlihat bahwa frekuensi tertinggi terletak pada kelas interval $(66,5-69,5)$. Hal ini menunjukan bahwa perilaku responden sikap tenggang rasa yang berada pada rentangan $(58-75)$ tinggi untuk sebagian responden.

Untuk mengetahui apakah data yang diperoleh berasal dari populasi berdistribusi normal atau tidak, maka dilakukan uji normalitas (liliefors). Kriteria uji normalitas adalah $\mathrm{H}_{1}$ diterima Lo hitung lebih besar dari Lo tabel, atau Ho diterima jika Lo hitung lebih kecil dari Lo tabel.

Dengan diterimanya $\mathrm{H}_{1}$ berarti data dalam penelitian berasal dari populasi berdistribusi normal, jika $\mathrm{H}_{1}$ ditolak berarti data berasal dari populasi berdistribusi tidak normal.

Setelah dilakukan perhitungan diperoleh Lo hitung sebesar 0,095. Jika dikonsultasikan dengan tabel Liliefors pada taraf signifikansi 0,05 dan $\mathrm{N}=40$ diperoleh Lo tabel 0,1401. Dengan demikian Ho diterima karena Lo hasil lebih kecil dari Lo tabel $(0,095$ $<0,1401)$. Sehingga dapat disimpulkan bahwa data variabel $\mathrm{X}$ berasal dari populasi berdistribusi normal.

Setelah dilakukan perhitungan diperoleh Lo hitung sebesar 0,75. jika dikonsultasikan dengan tabel Liliefors pada taraf signifikasi 0,05 dan $\mathrm{N}=40$ diperoleh Lo tabel 0,1401. dengan demikian $\mathrm{H}_{1}$ diterima karena Lo hasil lebih besar dari Lo tabel $(0,75$ $>0,1401$ ). Sehingga dapat disimpulkan bahwa data variabel $\mathrm{Y}$ berasal dari populasi berdistribusi normal.

Hasil perhitugan diperoleh $\mathrm{F}$ sebesar 1,390. Jika dikonsultasikan dengan $\mathrm{F}$ tabel taraf signifikansi 0,05 dengan $\mathrm{dk}(22,16)$ diperoleh $\mathrm{F}$ tabel 2,29. Dengan demikian hipotesis model linier diterima karena $\mathrm{F}$ hitung lebih kecil dari $\mathrm{F}$ tabel $(1,390<2,29)$.

Rumusan Hipotesis yang diajukan adalah Ho menyatakan bahwa "terdapat hubungan positif antara pengetahuan sila kemanusian dengan sikap tenggang rasa". Kriteria pengujian ditolak $\mathrm{H}_{1}$ dan diterima $\mathrm{Ho}$ jika $\mathrm{r}_{\text {hitung }}$ lebih kecil dari $\mathrm{r}_{\text {tabel }}$. Langkah yang ditempuh dalam menganalisis data dilakukan dengan menghubungkan dua jenis skor yaitu 
pengetahuan sila kemanusian dan skor sikap tenggang rasa. Rumusan untuk menganalisis data tersebut adalah rumus korelasi product moment. Dari perhitungan diperoleh $\mathbf{r}_{\text {hitung }}$ sebesar 0,311 . Koefisien korelasi $\mathrm{r}_{\mathrm{xy}}$ yang didapat tersebut kemudian dikonsultasikan pada tabel $\mathrm{r}$ product moment pada taraf signifikansi 0,05 dan $\mathrm{N}=40$ diperoleh dari $\mathrm{r}_{\text {tabel }}$ sebesar 0,312 . Dengan demikian $r_{\text {hitung }}$ lebih kecil dari $r_{\text {tabel }}(0,311<0,312)$. Berarti bahwa tidak terdapat hubungan antara pengetahuan sila kemanusian dengan sikap tenggang rasa terdapat hubungan yang positif, maka hipotesis penelitian ini ditolak karena $\mathrm{r}_{\text {hitung }}$ hasilnya menunjukan arah korelasi negatif.

Berdasarkan hasil analisis data diperoleh $\mathrm{r}_{\text {hitung }}$ lebih kecil dari $\mathrm{r}_{\text {tabel }}(0,311<$ 0,312). Hal ini menunjukkan bahwa tidak terdapat hubungan yang positif antara pengetahuan sila kemanusian dengan sikap tenggang rasa di SDN Cibarusah Jaya 01 Cibarusah. Sehingga dapat diinterprestasikan bahwa skor pengetahuan sila kemanusian dengan skor sikap tenggang rasa di SDN Cibarusah Jaya 01 Cibarusah tidak saling berhubungan.

\section{KESIMPULAN}

Penelitian ini secara emperis telah berhasil membuktikan tidak adanya hubungan pengetahuan sila kemanusian dengan sikap tenggang rasa di SDN Cibarusah Jaya 01 Cibarusah. Sebagai mana perhitungan uji $\mathrm{r}$ product moment pada taraf signifikan $\alpha=0,05$ dan $\mathrm{dk}=2,29$, yakni menghasilkan $\mathrm{r}$ hitung sebesar 0,311 lebih kecil t tabel sebesar 0,312. Dengan demikian hasil penelitian ini menyimpulkan bahwa tidak terdapat hubungan pengetahuan sila kemanusian dengan sikap tenggang rasa di SDN Cibarusah Jaya 01.

\section{DAFTAR PUSTAKA}

Bahan Penataran, (1990). Pedoman Penghayatan dan Pengamalan Pancadila. Jakarta: BP-7

C.S.T.Kansil, (1993). Hidup berbangsa dan Bernegara / Pedoman hidup bernegara untuk siswa Indonesia, Jakarta: Erlangga.

H.A.R. Tilaar, (1999). Manajemen Pendidikan dan Pengamalan Nasional, Bandung: PT. Remaja Rosdakarya.

Kasdi, dkk, (2004). LKS Pelita, Bogor: Arya Duta.

Marga Ruswanda, dkk, (1999). Belajar Efektif kewarganegaraan untuk SLTP I, Jakarta, Intimedia Cipta Nusantara. 